\title{
THE FRAMING OF WOMEN'S IDEAL BODY IN AMERICAN SOCIETY IN INSTAGRAM ILLUSTRATIONS BY JULIE HOUTS (@JOOLEELOREN)
}

\author{
Ni Wayan Eka Jayanti \\ e-mail: eka.jayanti.n@mail.ugm.ac.id \\ Ida Rochani Adi \\ Universitas Gadjah Mada \\ e-mail: idaadi@ugm.ac.id
}

\begin{abstract}
This study aims to learn about the framing of women's ideal body in Julie Houts' illustrations and the factors that shape the frames. Conducted within American Studies, this study borrows Entman's framing theory. This study applies qualitative and inductive methods to interpret the data. This study found that the framing highlights how women's ideal body is limited to one body type. A thin, youthful appearance is often considered the ideal appearance for women. Tan skin is another aspect regarded as the ideal appearance for women. Thinness, youthful appearance, and tan skin are desired because they signify health, reflecting society's obsession with health. The obsession with health often renders health a matter of appearance and gives power to those who look "healthy." The benefits of having the ideal body often outweigh the risks women may bear from pursuing the ideal body. As women's ideal body is limited to a thin, youthful appearance with tan skin, discrimination often occurs against women who do not match the ideal. Circumstances in society and the perception of women's bodies become the factors that shape what is considered the ideal body.
\end{abstract}

Keywords: framing; health; tan skin; thinness; women's ideal body; youthfulness

DOI $\quad$ : https://doi.org/10.22146/rubikon.v7i2.62751

Available at https://jurnal.ugm.ac.id/rubikon/article/view/62751

This work is licensed under a Creative Commons Attribution-ShareAlike 4.0 International License

\section{INTRODUCTION}

Many people today use social media to express their opinion. In particular, Instagram is a favorite of many people who want to share their thoughts in photographs or illustrations. Julie Houts, a Brooklyn-based illustrator, is
Article information

Received: 17 August, 2020

Revised: 31 August, 2020

Accepted: 14 September, 2020 one of many people who choose Instagram as a place to share her thoughts. Known as @ jooleeloren on Instagram, Houts has about 200 thousand followers. Formerly a womenswear designer, she now draws illustrations for many brands and magazines, such as On Pedder, Bergdorf Goodman, and 
The New Yorker. She also published two illustration books, Literally Me (2017) and Thank You for Being a Friend (2020). Houts' drawing style and humorous illustrations are two factors that draw the researcher's interest. In the comments for Houts' illustrations, the researcher found that many women are interested in Houts' illustrations due to their relatability. Many women write comments pointing out how the stories in Houts' illustrations remind them of their personal experiences. Indeed, many of Houts' capture American women's experiences in daily life. The content of Houts' illustrations gives a meaningful insight into the lives of American women. Houts' illustrations capture a wide range of women's experiences, but this study focuses on illustrations that address women's ideal body. This study aims to learn about the framing of women's ideal body in Julie Houts' illustrations. This study also aims to learn about the factors that shape the way women's ideal body is framed.

In analyzing the framing of women's ideal body, this study applies the qualitative method. In qualitative research, researchers are to "explicitly identify reflexively their biases, values, and personal backgrounds, such as gender, history, culture, and socioeconomic status (SES) that shape their interpretations formed during a study" (Creswell and Creswell, 2018, p. 260). This study also applies an inductive method, which means the researcher needs to look for patterns from the "bottom up" (Creswell and Creswell, 2018, p. 257). Then, these patterns are developed into a set of themes. American Studies, as an interdisciplinary study, often borrow methods and theories from other disciplines. This study borrows the framing theory by Robert $\mathrm{M}$. Entman, which originates from the communication field. In addition to that, this study focuses on the textual dimension of the illustrations. Hence, this study examines the text meanings (Gray, 2017) while also taking the time and place elements of the text into consideration.

Entman (1993, p. 52) stated that to frame means to "select some aspects of a perceived reality and make them more salient in a communicating text, in such a way as to promote a particular problem definition, causal interpretation, moral evaluation, and/or treatment recommendation." Per Entman's theory, this study starts with identifying the frames. Then, identifying and examining the highlighted elements. The highlighted elements are examined to learn about the problems and their causes, the evaluations of the problems, and/or the solutions. This study uses two types of data: primary data and secondary data. The primary data for this study consists of illustrations Houts posted on her Instagram account (@jooleeloren). They also include both drawing/image and text in Houts' illustrations. Secondary data for this study are collected from both library and internet sources (such as essays, books, magazines, papers). The data that has been collected and the highlighted elements are interpreted. The interpretation process also takes into account the elements of time and place of the text. Lastly, the results of the interpretation are organized into a general description. The description explains the framing of women's ideal body in Houts' illustrations and factors that shape the framing.

Julie Houts and her illustrations are discussed in many online articles. Tiffany Wood's article entitled Julie Houts is Basically Illustrating Your Life (2017) addressed Houts' former job as a womenswear designer and her creative process. Bridget Barnett's article 
entitled 10 Questions with Julie Houts (2019), discussed Houts' daily life and inspiration. In addition to that, the article discussed people's impression of Houts' illustrations. Karin Eldor's article entitled How Instagram Illustrator Julie Houts Went from Side Hustle to Full-Time Creative (2018) discussed Houts' past career in the fashion industry and her advice for freelance workers. Eldor's article also addressed the challenges in opening a business and the appeal of Houts' illustrations.

Meanwhile, the framing of American women has been discussed in prior studies. Laura L. Behling in Fisher's Bodies: Automobile Advertisements and the Framing of Modern American Female Identity (1997) examined images of American women in automobile advertisements. To be exact, Behling analyzed advertisements by Fisher Body Corporation. The advertisements are from magazines published between 1923 and 1934. The study revealed that these advertisements tend to reinforce traditional feminine womanhood (Behling, 1997). Michael Sheehy and Hong Ji in Framing the Ideal Woman in Esquire's "Women We Love," 1987-2006 (2011), examined women featured in Esquire's regular feature "Women We Love." Specifically, Sheehy and Ji focus on investigating the featured women's occupations and images. Their findings revealed that these women's occupations become less diverse, while their images become traditional (Sheehy and Ji, 2011). Marian McPherson in Framing of AfricanAmerican Women in Mainstream and Black Women's Magazine (2015) examined articles from two magazines, Glamour and Essence, published from 2009 to 2014. The results of McPherson's study revealed that the perception of African-American women become more varied but still show influences of black women stereotypes (McPherson, 2015). Nurlita Hapsari in Framing Women Politician in Democratic Environment: A Study of Megawati Soekarnoputri and Hillary Clinton (2017) focused on an Indonesian female politician (Megawati Soekarnoputri) and an American female politician (Hillary Clinton). To be specific, Hapsari examined the media framing of these politicians during the presidential campaign. Hapsari also analyzed its implication on gender conception in Indonesia and America. Data for this study are from Indonesian and American online news sources (Detik, Liputan6, Tempo, The New York Times, USA Today, The Washington Post, The Los Angeles Times, and The Wall Street Journal). Hapsari's study revealed that Indonesian and American media often highlight Megawati's and Clinton's appearance and family relations instead of work plans or political views (Hapsari, 2017).

While prior studies focus on the framing of American women, none of them discussed the framing of women's ideal body in Instagram illustrations. Behling examined advertisements, while McPherson, as well as Sheehy and $\mathrm{Ji}$, investigated magazines. Hapsari analyzed online news. Another difference is that this study concerns American women in general. This study does not focus on a particular female politician or women of a specific race or a certain period.This study focuses on women's ideal body in American society and the factors that shape the perception of women's ideal body.

\section{DISCUSSION}

This study found that the framing in Houts' illustrations highlights how women's ideal body must be thin and youthful. In addition to that, tan skin is considered another 
standard of women's ideal body. The three aspects that comprise women's ideal body are discussed one by one. In terms of thinness, there is a clear preference for women with thin bodies. The preference for thin women over fat women is prevalent in advertisements. In advertisements, thin women tend to appear more frequently than fat women. The preference for thin women is evident in Figure 1 .

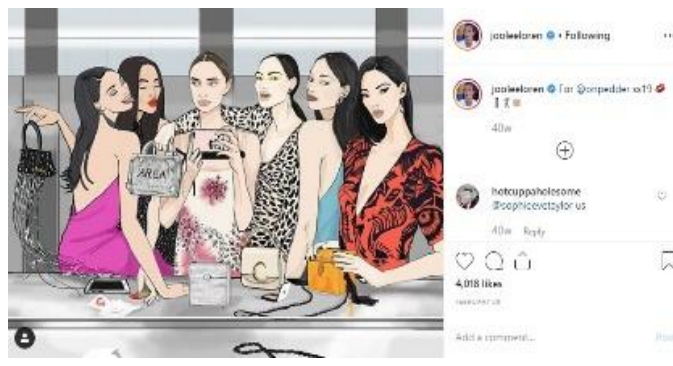

Figure 1. A Depiction of Thin Women in an Advertisement for On Pedder. Houts, J. [@jooleeloren]. (2019, February 28). For @onpedderss19 $\square$ [Photograph]. Instagram. https://www.instagram.com/p/BubYTphnYbO/

The illustration in Figure 1. is for the luxury brand On Pedder. There are six women in Figure 1., but they have a similar body type. These women evidently have thin arms and slim waist. The clothes they are wearing further accentuate their thin bodies. These women also have defined jaws and cheekbones. From the way Figure 1. depicts women in the same thin, slim body, it is clear that there is a preference for women with thin bodies.

Advertisements also tend to depict thin women positively. Thin women are portrayed to look attractive and fashionable. In Figure 1., all of the women look very attractive. They also wear stylish clothes that accentuate their thin bodies. Overall, the way Figure 1 portrays thin women is very flattering. The positive depiction of thin women and their frequent appearance in advertisements send a message that thin women are treated favorably. The absence of fat women in advertisements shows that they are still underrepresented in the media. Prior studies have analyzed the lack of fat women in media. White et al (1999) found that women on television programs are portrayed with slimmer bodies, in less diverse body types than men. Greenberg et al. (2003), who also examined television programs, found that thin bodies are more prevalent among women. In addition to that, thin women tend to be portrayed more positively than fat women (Greenberg et al., 2003). These studies support the findings that thin women are preferred over fat women, particularly in media. These studies also support the findings that thin women are portrayed with positive characteristics.

Thin bodies are highly desirable today. Thin bodies are also associated with positive attributes. According to Gracia-Arnaiz (2010, p. 221), thin bodies are considered indicators of "good health, self-discipline, and social distinction." While thin bodies are associated with good health, fat bodies are often associated with illness. The National Institute of Diabetes and Digestive and Kidney Diseases stated that excess weight potentially increases the risk of obesity-related diseases (diabetes, strokes, heart disease, kidney disease, cancer, osteoarthritis, fatty liver disease, sleep apnea, high blood pressure). Fat people are often associated with negative characteristics, such as laziness and lacking willpower (Teachman and Brownell, 2001).

Unlike thin bodies, fat bodies today are undesirable and have a negative image in society. However, when food was scarce, many people favored fat bodies. The scarcity of food made the ability to store fat from a limited amount of food is essential for survival (Eknoyan, 2006). Eknoyan (2006) asserted 
that at the time, fat bodies mean power, influence, wealth, prosperity, health, and strength. In contrast, thin bodies mean poverty, hunger, and illness (Gracia-Arnaiz, 2010, p. 220). Today, fatness is considered a behavioral problem (Foster et al., 2003). Physical inactivity, overeating, and a high-fat diet are considered the primary causes of weight gain (Foster et al., 2003). The perception that fatness is a behavioral problem makes people see their weight as individual responsibility. The possession of a fat body is considered a failure in managing one's lifestyle.

However, regardless of their weight, women tend to feel dissatisfied with their bodies. When women appear to have thin bodies after participating in weight loss activities, their negative perception of their bodies remains. Figure 2. illustrates this dissatisfaction.

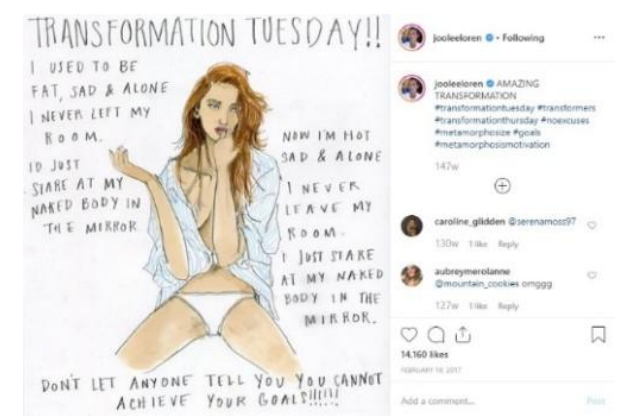

Figure 2. A Woman's Dissatisfaction of Her Bodies Post Weight Loss.Houts, J. [@jooleeloren]. (2017, February 10). AMAZING TRANSFORMATION \#transformationtuesday \#transformers \#transformationt hursday \#noexcuses \#metamorphosize \#goals \#metamor phosismotivation [Photograph]. Instagram.https://www.instagram.com/p/BQTqhp B Vj/

Figure 2. shows a woman wearing an unbuttoned shirt, which reveals her slim body. However, it turns out that she does not have a slim body in the past. The text in Figure 2. reveals that she was fat. The text also shows how she feels "sad and alone" when she was fat (Houts, 2017). She admits that she only stays in her room during those times to stare at her naked body. The negative feeling of her body, interestingly, remains after she loses weight and becomes slim. She still feels "sad and alone" and keeps watching her naked body in her room (Houts, 2017). From her feeling and behavior after weight loss, having a thin body does not seem to erase her dissatisfaction and anxiety from having a fat body. It seems that no matter her weight, she will always feel bad about her body. Although the illustration is titled "Transformation Tuesday," almost there is no change in her.

Women's dissatisfaction with their bodies, regardless of their weight, reflects Neighbors and Sobal's study. Neighbors and Sobal (2007) found that women show a greater dissatisfaction about their body weight and shape than men. They want to be slimmer and lighter even though most of them have a normal weight (Neighbors and Sobal, 2007). According to McCaulay et al. (1998), women tend to see themselves to be larger or heavier than their actual weight. In addition to that, the ideal female body is becoming thinner while women are becoming larger and heavier (Spitzer et al., 1999). Women's perception of their bodies and the gap between women's bodies and the ideal body shape women's body dissatisfaction. They become a harsh judge of their weight and feel dissatisfied with their bodies more frequently.

There is an increasing attempt to normalize fatness. It is evident from how fat women promote confidence in their fat bodies by wearing clothes typically designed to accentuate thin bodies, such as a mini dress or bikini. Their sense of confidence in their clothing style sends a message that having a fat body is not shameful. Their attitude and their clothing style show that women should not conceal their fat bodies. It is because fatness is normal. Although the attempts to 
normalize fatness is increasing, it is clear that fat women largely remain invisible. It shows that the thin ideal is still prevalent in society, and a fat body is still considered a "deviation" from the ideal.

Women can also develop a negative perception of their bodies due to a comparison with female models. A comparison with female models often makes women perceive themselves to be less attractive. It can also make them feel dissatisfied with their bodies. Similarly, Richins (1991) reported that women express less satisfaction with their appearance after exposure to images of attractive models. This way, it is clear that exposure to images that show the ideal body causes women to develop a negative perception of their bodies. The higher the frequency of exposure, the less attractive and less satisfied they feel with their bodies.

Franzoi and Klaiber (2007) found that, while people often compare themselves to others with similar bodies, women often compare themselves to attractive models. In particular, in terms of weight and sexual attractiveness (Franzoi and Klaiber, 2007). For women, their appearance is an essential aspect of their lives. Women learn to value their appearance. They also invest more in their appearance. The importance of their appearance makes it crucial for women to achieve the beauty ideal. Models, who represent the beauty ideal, make the perfect standard for evaluation. By comparing themselves to models, women can find out if they achieve the ideal.

In addition to thin bodies, a youthful appearance is considered an aspect that makes women's ideal body. The clear preference for youthful appearance often results in the invisibility and exclusion of older women. The invisibility and exclusion that older women experience are evident in Figure 3.

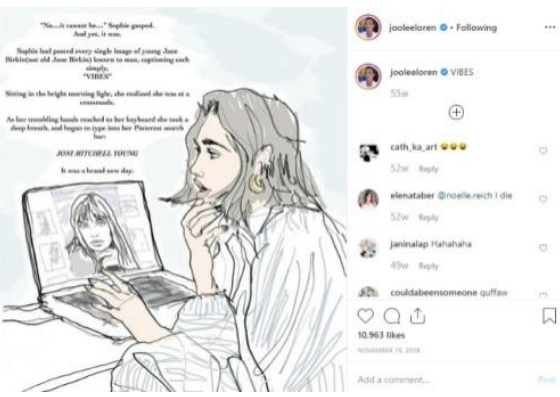

Figure 3. A Woman's Obsession with Female Celebrities' Youthful Appearance.Houts, J. [@jooleeloren]. (2018, November 15). VIBES [Photograph]. Instagram https://www.instagram.com/p/BqLR7KmnroZ/

Figure 3. illustrates a young woman called Sophie, who seems to obsess over young Jane Birkin and Joni Mitchell. Figure 3. also elaborates how Sophie loves to collect and post every single photograph of young Jane Birkin and Joni Mitchell. Sophie even emphasizes that she is collecting pictures of the younger version of these celebrities only, not their older selves. It is apparent from the way Sophie always add "young" to these celebrities' names. She always says "young Jane Birkin" or "Joni Mitchell young" (Houts, 2018). In addition to that, when mentioning how she has posted every single picture of Jane Birkin, she emphasizes that she posted photographs of young Jane Birkin and not old Jane Birkin. The young woman's preference for the younger version of female celebrities reflects society's preference for younger women. Her preference for young women also reveals how women become invisible as they age. Sophie's refusal to post pictures of older women seems to create a message that women are no longer become a person's priority as they are getting older. It reflects Hurd Clarke and Griffin's findingthat older women after age 50 often become invisible (2008, p. 669). In particular, as potential employees or 
romantic partners (Hurd Clarke and Griffin, 2008). The perception that considers women's aging bodies a "deviation" from the beauty ideal causes older women's invisibility in society (Hurd Clarke and Griffin, 2008, p. 669).

Older women are not the only ones who experience age discrimination. Age discrimination also occurs in older men. Roscigno et al. (2007) found that older women and men are more vulnerable to demotion, dismissal, and harassment. They may also be denied a promotion or rejected when looking for a job (Roscigno et al., 2007). It is interesting that older men are often told to be too experienced for a job (McMullin and Berger, 2006). However, older women are discriminated against due to their appearance. In research by Roscigno et al. (2007), older women are discriminated against in their workplace because their image or appearance does not fit the company profile. Likely, this difference is caused by the different perceptions of women's and men's bodies. Women's bodies tend to be viewed in terms of their beauty, while men's bodies of their functionality (Franzoi, 1995). While women focus on body parts that reflect beauty (such as the face, lips, chest, legs, or buttocks), men focus on health, agility, reflexes, strength, or coordination (Franzoi, 1995, p. 418). People may internalize these perceptions, which then shape their different treatment towards older women and men.

Today, older people tend to receive unfavorable treatment. People often consider old age as being unproductive, frail, senile, and sick (Minichiello, 2000; Palmore, 1978,p. 214). People also perceive older people as of lower status (Cuddy and Fiske, 2002, p. 17). Society today tend to perceive older people as unimportant and insignificant. However, older people in the past were highly respected individuals. Nelson $(2005$, p. 208) stated that in prehistoric and agrarian societies, in particular, older people were regarded as teachers. Nelson also stated thatthey were considered guardians of the traditions and history of their people (2005, p. 208). Older people had extensive experiences, which explains the respect their people had for them (Nelson, 2005, p. 208). It contrasts with the situation today, in which older people often lose their jobs and access to vital resources.

Women often perceive the process of aging as something they must avoid. Women fear looking old as it can deprive them of vital resources. This fear stands out even more when considering that older women often get unfair treatment due to their aging appearance. The fear of looking old then drives women to preserve their youthful appearance or conceal their age using anti-aging products. However, this study found that aging is inevitable and anti-aging products are hardly effective in stopping the aging process. Figure 4. captures this reality.

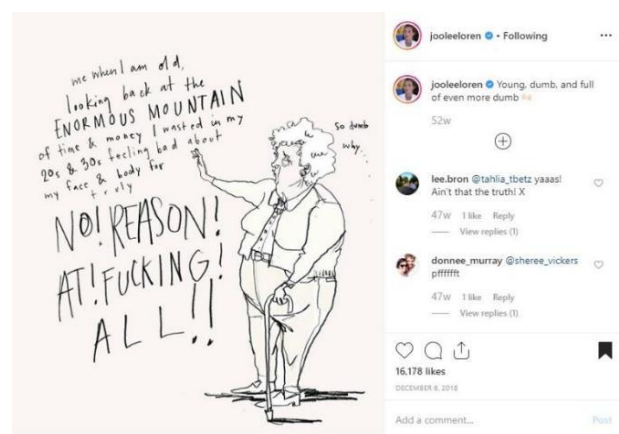

Figure 4. An Older Woman Questioning Beauty Products She Used in Her Youth. Houts, J. [@jooleeloren]. (2018, December 6). Young, dumb, and full of even more dumb [Photograph]. Instagram.https://www.instagram.com/p/BrBSw93Htg2/

Figure 4. illustrates an older woman expressing her regret about numerous products she used in her youth. Figure 4 does not 
explicitly address aging, but the drawing of an older woman and the text about her appearance maintenance points to aging. She says how she has spent an enormous amount of time and money in her $20 \mathrm{~s}$ and $30 \mathrm{~s}$ to maintain her appearance. She feels bad about her appearance, which explains her investment in appearance. However, now that she has aged, she regrets spending so much time and money on appearance. The story about her appearance maintenance and the image of present her, which emphasizes her aged appearance, seem to capture the reality of aging and anti-aging products. Figure 4 . does not mention anti-aging products, but it is clear that she aims to look young even when she has aged. Thus, it is highly likely that she also uses anti-aging products. By doing appearance maintenance from an early age, the woman hopes to preserve her youthful appearance. Despite her effort, she cannot avoid the process of aging, which explains her regret and the drawing of her older self. Women cannot prevent aging despite the meticulous appearance maintenance they do since their youth.

The use of anti-aging products to avoid aging implies that women believe they can control aging if they use certain products. It reflects the belief in the United States, which considers aging a sickness that they can treat and cure (Calasanti and Slevin, 2006, p. 16). However, because people believe that they can control aging and have the means to do it, they become more pressured to avoid looking old (Calasanti, 2007). For women, this pressure drives them to maintain their youthful appearance since they are still very young. It makes women engage in a lifelong pursuit of the ideal appearance, marked by anxiety and never-ending consumption to maintain their appearance.
This study also found that the framing highlights tan skin as an aspect of women's ideal body. In particular, the framing highlights how women purposely tan their skin despite knowing the health risks of tanning. Overexposure to UV light can result in sunburn, premature skin aging (Fisher et al., 2002), and skin cancer (Garone et al., 2015). However, these health risks do not discourage women from tanning their skin. In Figure 5., a woman with sunburn all over her body is looking at another woman with tan skin. The sunburnt woman is looking at the tan woman with longing on her eyes, implying that she desires tan skin. She experiences the sideeffect of tanning but still wants tan skin. Her desire for tan skin is so powerful that she disregards the side-effect she received from tanning. Seeing her behavior, it is clear that the danger of tanning does not deter her from pursuing tan skin. It reflects Poorsattar and Hornung's study (2007) that a recent history of sunburn makes current tanners change their behavior. Family history of skin cancer (Knight et al., 2002; Poorsattar and Hornung, 2007) also fail to alter their behavior.

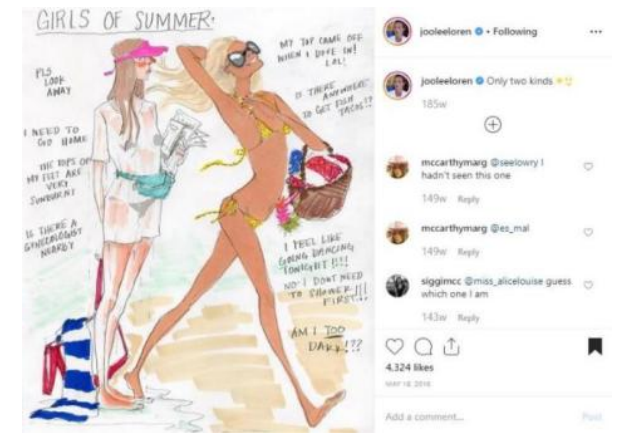

Figure 5. A Woman with Mild Sunburn Comparing Herself to a Woman with Tan Skin.Houts, J. [@jooleeloren]. (2016, May 18). Only two kinds淙 $\square$.Instagram. https://www.instagram.com/p/BFg8xWbpwI4/

This study found that the desire to have an attractive appearance tends to be the factor that motivates women to tan their skin despite the risks. The tan woman in Figure 5. looks 
confident and attractive. The tan woman does not hesitate to flaunt her body by wearing a bikini that covers very little. The attractiveness of $\tan$ skin likely explains the sunburnt woman's desire for tan skin. The sunburnt woman believes that the possession of tan skin makes her look attractive. Indeed, prior research (Knight et al., 2002; Poorsattar and Hornung, 2007) revealed that tanners' primary motivation to tan their skin is indeed related to appearance. Considering the primary motivation for tanning, it is clear that the reward of tanning (the possession of an attractive appearance) outweighs the health risks of tanning. It explains why women want to have tan skin despite experiencing the danger of tanning.

In addition to that, tan skin is associated with positive characteristics. Health, vitality, youthfulness, and beauty are some positive characteristics that people associate with tan skin (Hurd Clarke and Korotchenko, 2009, p. 758). According to Gillen and Bernstein (2015), many people also believe that people with tan skin possess enhanced social skills. Those with tan skin are also believed to excel in jobs where social skill is necessary (Gillen and Bernstein, 2015). Today, many people, especially women, prefer tan skin. However, people in the past favored pale skin as it symbolized the absence of manual labor (Gillen and Bernstein, 2015; Keesling and Friedman, 1978). The introduction of heliotherapy to America in 1914 is often considered the reason for people's interest in tan skin (Keesling and Friedman, 1978). It is said that heliotherapy shaped the perception of tan skin as an indicator of good health and pale skin of poor health (Keesling and Friedman, 1978). The Industrial Revolution and the influence of Coco Chanel are also considered the factors that change people's perception of tan skin (Keesling and Friedman, 1978).

While American women usually favor tan skin, Asian women tend to favor fair skin. Asian women often associate fair skin with a happy love life or marriage, enhanced selfesteem or confidence, and career success (Cuny and Opaswongkarn, 2017; Hussein, 2010). Asian women often use skin-whitening products to get fair and bright skin. However, these products can be dangerous for the safety of the skin. They can cause skin problems such as skin atrophy, acne vulgaris, or redness (Yusuf et al., 2019, p. 354). While American and Asian women have a different skin color preference, they behave similarly in pursuing their preferred skin color. Both tanning and skin bleaching can be dangerous for the skin, but these women often ignore this danger to get their desired skin color. Their behavior shows how appealing the benefits of having desirable skin color are. Women, in particular, perceive appearance as an essential aspect of their lives. The importance of their appearance explains women's willingness to engage in risky appearance-altering practices.

Women's ideal body highlighted by the framing is consistently associated with health. According to Cheek (2008, p. 974), Western societies today perceive health as something "sacred." The association between women's ideal body and health reflects the holiness of health in Western societies. Many people today want to be healthy. In addition to that, the definition of health has developed to encapsulate physical, mental, and social problems. According to the World Health Organization (WHO), health is "a state of complete physical, mental and social wellbeing and not merely the absence of disease or infirmity." People's understanding of health 
becomes more complex and holistic. Health no longer means the absence of illness. Today, being healthy means being "physically whole and vigorous" and "happy and socially content" (Fitzgerald, 1994, p. 196). Because of that, clean eating or applying skin-nourishing oil can be as essential as prescriptions for medicine for health. The industry encourages people's obsession with health by promoting organic foods, green products, or workout plans. When people spend their time and money maintaining their health, it is considered their display of obedience to their duties and obligations as citizens (Ayo, 2012, p. 101). In addition to that, health is considered an indicator of a person's qualities. "Unhealthy" people are perceived as "morally flawed and irresponsible" (Preston, 2015, p. 22). Today, health is considered to be a personal responsibility. "Unhealthy" people are perceived to have failed in maintaining their health and lifestyle. Their failure to maintain their health and lifestyle means that they have failed to fulfill their responsibility. In contrast, "healthy" people are often perceived as role models (Crawford, 1980).

The perception of health shape the way a person views themselves and other people. The framing in Houts' illustrations highlights how women feel superior when they engage in practices that make them appear "healthy" (such as exercise or clean eating). They tend to brag about their healthy activities and belittle others who do not do the same. This behavior is evident in Figure 6., which illustrates a woman post-exercise. She explicitly says that she goes to the gym to "feel the awesome wave of smug superiority," which allows her "to look down on virtually everyone \& everything" (Houts, 2018). She does not go to the gym because she wants to lose weight, enhance her strength, or get "mental clarity" (Houts, 2018).
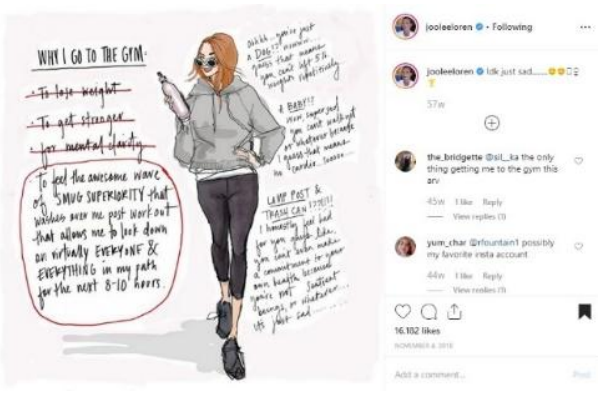

Figure 6. A Woman Who Feels Superior After Exercising. Houts, J. [@jooleeloren]. (2018, November 4).Idk just sad....... [woman in lotus position emoji] [Photograph].Instagram.https://www.instagram.com/p/BpusmwG nFqx/

Figure 6. then elaborates how she brags about her exercise to those she deems "unhealthy" because they cannot exercise like her. She also expresses her sadness at these "unhealthy" beings for their inability to commit to their health. Her behavior suggests that she exercise not because she wants to take care of her health but to feel superior. This way, women's health practices seem to be more about appearance than a genuine attempt to maintain health. Preston (2015) also suggested a similar point, that health has become defined as "looking a particular way"(p. 134). Their obsession with healthy appearance erases the essence of healthy practices, which is to maintain physical, mental, and social wellbeing.

\section{CONCLUSION}

To conclude, the framing of American women in Houts' illustrations highlights women's ideal body. Women's ideal body comprises of a thin and youthful appearance and tan skin. The framing also highlights the way this ideal shapes women's behavior and perception of their bodies. Unfortunately, women tend to put themselves at risk in pursuing this ideal. Appearance-altering 
practices they are engaged in often endanger their health. It is ironic, considering the consistent association between women's ideal body and health. The ideal also shapes women's consumption of beauty products. In addition to that, the framing highlights the impact of limiting women's ideal body on one body type. Women who do not conform to the ideal tend to get unfavorable treatment from others. The pursuit of the ideal body also makes women develop a negative perception of their bodies. They often become dissatisfied and anxious with their bodies, even when their bodies already match the ideal. The possession of the ideal body comes with benefits, but it often crushes women's confidence in their bodies. The changing circumstances and the perception of women's bodies often shape women's ideal bodies to what it is today.

\section{REFERENCES}

Ayo, N. (2012). "Understanding Health Promotion in a Neoliberal Climate and the Making of Health Conscious Citizens." Critical Public Health, 22(1), 99-105. DOI:10.1080/09581596.2010.520692.

Barnett, B. (2019, February 28). "10 Questions with Julie Houts." On Pedder. Retrieved from

https://www.onpedder.com/2019/02/10questions-with-julie-houts/.

Behling, L. L. (1997). "Fisher's Bodies: Automobile Advertisements and the Framing of Modern American Female Identity." The Centennial Review, 41(3), 515-528. Retrieved from https://www.jstor.org/stable/23740669.

Calasanti, T. (2007). "Bodacious Berry, Potency Wood and the Aging Monster: Gender and Age Relations in Anti-Aging Ads." Social Forces, 86(1), 335-355. DOI: 10.1353/sof.2007.0091.
Calasanti, T. M., \& Slevin, K. F. (2001). Gender, Social Inequalities, and Aging. Altamira Press.

Cheek, J. (2008). "Healthism: A New Conservatism?" Qualitative Health Research, 18(7), 974-982. DOI:10.1177/1049732308320444.

Crawford, R. (1980). "Healthism and the Medicalization of Everyday Life." International Journal of Health Services, 10(3), 365-388. DOI:10.2190/3H2H3XJN-3KAY-G9NY.

Creswell, J. W., \& Creswell, J. D. (2018). Research Design: Qualitative, Quantitative, and Mixed Methods Approaches (5th ed.). SAGE Publications.

Cuddy, A. J. C., and Fiske, S. T. (2002). "Doddering but Dear: Process, Content, and Function in Stereotyping of Older Persons." In T. D. Nelson (Ed.), Ageism: Stereotyping and Prejudice against Older Persons, 3-26. The MIT Press.

Cuny, C., \& Opaswongkarn, T. (2017). "Why do Young Thai Women Desire White Skin? Understanding Conscious and Nonconscious Motivations of Young Women in Bangkok. Psychology \& Marketing, 34(5), 556-568. DOI: 10.1002/mar.21005.

Eknoyan, G. (2006). "A History of Obesity, or How What Was Good Become Ugly and Then Bad." Advances in Chronic Kidney Disease, 13(4), 421-427. DOI:10.1053/j.ackd.2006.07.002.

Eldor, K. (2018, February 2). "How Instagram Illustrator Julie Houtswent from Side Hustle to Full-Time Creative." Forbes. Retrieved from https://www.forbes.com/sites/karineldor/2 018/02/02/how-instagram-illustrator-juliehouts-went-from-side-hustle-to-full-timecreative/?sh $=61 \mathrm{f} 9 \mathrm{~d} 3132 \mathrm{e} 37$.

Entman, R. M. (1993). "Framing: Toward Clarification of a Fractured Paradigm." Journal of Communication, 43(4), 51-58. 
DOI:10.1111/j.1460-

2466.1993.tb01304.x.

Fisher, G. J., Kang, S., Varani, J., BataCsorgo, Z., Wan, Y., Datta, S., \& Voorhees, J. J. (2002). "Mechanism of Photoaging and Chronological Skin Aging." Archives of Dermatology, 138(11), 1462-1470.

DOI:10.1001/archderm.138.11.1462.

Fitzgerald, F. T. (1994). "The Tyranny of Health." The New England Journal of Medicine, 331(3), 196-198. DOI: 10.1056/NEJM199407213310312.

Foster, G. D., Wadden, T. A, Makris, A. P., Davidson, D., Sanderson, R. S., Allison D. B., \& Kessler, A. (2003). "Primary Care Physicians' Attitudes about Obesity and Its Treatment." Obesity Research, 11(10), 1168-1177. DOI:10.1038/oby.2003.161.

Franzoi, S. L. (1995). "The Body-As-Object versus the Body-As-Process: Gender Differences and Gender Considerations." Sex Roles, 33(5/6), 417-437. DOI:10.1007/BF01954577.

Franzoi, S. L., \& Klaiber, J. R. (2007). Body Use and Reference Group Impact: With Whom Do We Compare Our Bodies?" Sex Roles, 56, 205-214.DOI:10.1007/s11199. 006-9162-4.

Garone, M., Howard, J., \& Fabrikant, J. (2015). "A Review of Common Tanning Methods." The Journal of Clinical and Aesthetic Dermatology, 8(2), 43-47. Retrieved from https://www.ncbi.nlm.nih.gov/pmc/article s/PMC4345932/

Gillen, M. M., \& Bernstein, M. J. (2015). "Does Tanness Mean Goodness? Perceptions of Tan Skin in Hiring Decisions." North American Journal of Psychology, 17(1), 1-15.

Gracia-Arnaiz, M. (2010). "Fat bodies and Thin Bodies. Cultural, Biomedical and Market Discourses on Obesity." Appetite, 55(2), 219-225. DOI:10.1016/j.appet.2010.06.002.
Gray, J. (2017). “Text.” In L. Oullette \& J. Gray (Eds.), Keywords for Media Studies (ch. 65). New York UP.

Greenberg, B. S., Eastin, M., Hofschire, L., Lachlan, K., \& Brownell, K. D. (2003). "Portrayals of Overweight and Obese Individuals on Commercial Television." American Journal of Public Health, 93(8), 1342-1348.

DOI:10.2105/AJPH.93.8.1342.

Hapsari, N. (2017). "Framing Women Politician in Democratic Environment: A Study of Megawati Soekarnoputri and Hillary Clinton." Rubikon, 4(1), 11-29. DOI:https://doi.org/10.22146/rubikon.v4i 1.47858

Hurd Clarke, L., \& Griffin, M. (2008). "Visible and Invisible Ageing: Beauty Work as a response to Ageism." Aging \& Society, 28, 633-674. DOI:10.1017/S0144686X07007003.

Hurd Clarke, L., \& Korotchenko, A. (2009). "Older Women and suntanning: The Negotiation of Health and Appearance Risks." Sociology of Health \& Illness, 31(5), 748-761. DOI:10.1111/j.14679566.2009.01175.x.

Hussein, N. (2010). "Colour of Life Achievements: Historical and Media Influence of Identity Formation based on Skin Colour in South Asia." Journal of Intercultural Studies, 31(4), 403-424. DOI:10.1080/07256868.2010.491275.

Keesling, B., \& Friedman, H. S. (1978). "Psychosocial Factors in Sunbathing and Sunscreen Use." Health Psychology, 6(5), 477-493. DOI:10.1037/02786133.6.5.477.

Knight, J. M., Kirincich, A. N., Farmer, E. R., \& Hood, A. F. (2002). "Awareness of the Risks of Tanning Lamps Does Not Influence Behavior among College Students." Archives of Dermatology, 138(10), 1311-1315. DOI:10.1001/archderm.138.10.1311. 
McCaulay, M., Mintz, L., \& Glenn, A. A. (1998). "Body Image, Self-Esteem, and Depression-Proneness: Closing the Gender Gap." Sex Roles, 18(7/8), 381391. DOI:10.1007/BF00288390.

McMullin, J. A., \& Berger, E. D. (2006). "Gendered Ageism/Age(ed) Sexism: The Case of Unemployed Older Workers." In T. M. Calasanti \& K. F. Slevin (Eds.), Age Matters: Realigning Feminist Thinking, 201-223. Routledge.

McPherson, M. (2015). Framing of AfricanAmerican Women in Mainstream and Black Women's Magazine. [Master thesis, University of Missouri]. MOspace Institutional Repository. Retrieved from https://hdl.handle.net/10355/46591

Minichiello, V., Browne, J., \& Kendig, H. (2000). "Perceptions and Consequences of Ageism: Views of Older People." Aging and Society, 20, 253-278. DOI:10.1017/S0144686X99007710.

National Institute of Diabetes and Digestive and Kidney Diseases. (February 2015). Health Risks of Being Overweight. Retrieved from https://www.niddk.nih.gov/healthinformation/weight-management/healthrisksoverweight\#: :text=Obesity\%20increases $\% 20$ the $\% 20$ risk $\% 20$ of,disease $\% 20$ and $\%$

Neighbors, L. A., \& Sobal, J. (2007). "Prevalence and Magnitude of Body Weight and Shape Dissatisfaction among University Students." Eating Behaviors, 8, 429-439.

DOI:10.1016/j.eatbeh.2007.03.003

Nelson, T. D. (2005). "Ageism: Prejudice against Our Feared Future Self." Journal of Social Issues, 61(2), 207-221. DOI:10.1111/j.1540-4560.2005.00402.x.

Palmore, E. (1978). "Are the Aged a Minority Group?" Journal of the American Geriatrics Society, XXVI(5), 214-216. DOI:10.1111/j.15325415.1978.tb01961.x.
Poorsattar, S. P., \& Hornung, R. L. (2007). "UV Light Abuse and High-Risk Tanning Behavior among Undergraduate College Students." Journal of the American Academy of Dermatology, 56(3), 375-379. DOI:10.1016/j.jaad.2006.08.064.

Preston, S. L. (2015). Bearing the Weight of Healthism: A Critical Discourse Analysis of Women's Health, Fitness, and Body Image in the Gym. [Doctoral Dissertation, Arizona State University]. ASU Digital Repository. Retrieved from http://hdl.handle.net/2286/R.I.53811

Richins, M. L. (1991). "Social Comparison and the Idealized Images of Advertising." Journal of Consumer Research, 18(1), 7183. Retrieved from https://www.jstor.org/stable/2489486

Roscigno, V. J., Mong, S., Byron, R., \& Tester, G. (2007). "Age Discrimination, Social Closure and Employment." Social Forces, 86(1), 313-334. DOI:10.1353/sof.2007.0109.

Sheehy, M.,\& Ji, H. (2011). "Framing the Ideal Woman in Esquire's 'Women We Love,' 1987-2006." Journal of Magazine \& New Media Research, 12(2), 1-17. Retrieved from aejmcmagazine.arizona.edu/summer2011. html.

Spitzer, B. L., Henderson, K. A., \& Zivian, M. T. (1999). "Gender Differences in Population versus Media Body Sizes: A Comparison over Four Decades." Sex Roles, 40(7/8), 545-565. DOI:10.1023/A:1018836029738.

Teachman, B. A., \& Brownell, K. D. (2001). "Implicit Anti-Fat Bias among Health Professionals: Is Anyone Immune?" International Journal of Obesity, 25, 1525-1531. DOI:10.1038/sj.ijo.0801745.

White, S. E., Brown, N. J., \& Ginsburg, S. L. (1999). "Diversity of Body Types in Network Television Programming: A Content Analysis." Communication 
Research Reports, 16(4), 386-392. DOI:10.1080/08824099909388740.

Wood, T. (2017, May 2). "Julie Houts is Basically Illustrating Your Life." Galore. Retrieved from https://galoremag.com/julie-houtsillustrator-jooleeloren/

World Health Organization. Constitution. Retrieved from https://www.who.int/about/who-weare/constitution

Yusuf, M. A., Mahmoud, N. D., Rirash, F. R., Stoff, B. K., Liu, Y., \& McMichael, J. R.(2019). "Skin Lightening Practices, Beliefs, and Self-Reported Adverse Effects among Female Health Science Students in Borama, Somaliland: A CrossSectional Survey." International Journal of Women's Dermatology, 5(5), 349-355. DOI:10.1016/j.ijwd.2019.08.006. 